\title{
Dexamethasone inhibits TGF- $\beta 2$-induced migration of human lens epithelial cells: Implications for posterior capsule opacification prevention
}

\author{
JIN YAO*, WEN YANG* , YUAN LIU, YAN-XI SUN and QIN JIANG \\ The Affiliated Eye Hospital of Nanjing Medical University, Nanjing 210029, P.R. China
}

Received August 15, 2011; Accepted November 7, 2011

DOI: $10.3892 / \mathrm{mmr} .2012 .827$

\begin{abstract}
The elevation of transforming growth factor- $\beta_{2}$ (TGF- $\beta_{2}$ ) levels in eye tissue is considered as one of the major factors contributing to posterior capsule opacification (PCO) in patients undergoing cataract surgery, since TGF- $\beta_{2}$ is known to stimulate the cell migration of residual human lens epithelial cells (HLECs). The present study aimed to test the potential effect of dexamethasone (DEX) on TGF- $\beta_{2}$-induced cell migration and the possible cellular mechanisms involved in this process. Cultured HLE-B3 cells were treated with TGF- $\beta_{2}$ $(0.1 \mathrm{ng} / \mathrm{ml})$ in the presence or absence of DEX $(100 \mathrm{nM})$. HLE-B3 cell migration was determined by the Phagokinetic Track Motility Assay. Activation of mitogen-activated protein kinase (MAPK) signaling pathways was determined by Western blotting using specific phosphorylation antibodies, matrix metalloproteinase (MMP)-2 and MMP-9 mRNA expression, and activities were analyzed by RT-PCR and gelatin zymography assay, respectively. In cultured HLE-B3 cells, DEX largely inhibited TGF- $\beta_{2}$-induced cell migration and MMP activity, probably by inhibiting the ERK/MAPK pathway. We suggest that the use of DEX may be of help in the prevention of PCO formation and development.
\end{abstract}

\section{Introduction}

Posterior capsule opacification (PCO) is the leading cause for secondary vision impairment and loss in patients with cataract surgery. Primarily due to the improvement of surgical techniques and the advancement of implantation materials, the incidence of PCO in recent years is lower. However, PCO

Correspondence to: Dr Qin Jiang, The Affiliated Eye Hospital of Nanjing Medical University, 138 Han-Zhong Road, Nanjing 210029, P.R. China

E-mail: jqin710@vip.sina.com

*Contributed equally

Key words: dexamethasone, transforming growth factor- $\beta 2$, human lens epithelial cell migration, matrix metalloproteinases, mitogenactivated protein kinase remains one of the major concerns in routine clinical practice. By far, the only effective treatment for PCO is Nd:YAG laser capsulotomy. However, in addition to its cost burden, it carries other complications and risks, and is difficult to be performed on children and infants $(1,2)$. Therefore, alternative treatments, including pharmacological strategies to prevent $\mathrm{PCO}$ formation, are highly desirable. In spite of many efforts made towards this goal, there is no drug or medical pre-treatment available for the prevention or amelioration of PCO $(3,4)$.

The pathogenic mechanism of PCO is not fully understood, but recent studies suggest that PCO may be caused by several reasons, including residual lens epithelial cell proliferation and migration, epithelial-mesenchymal transition, collagen deposition and lens fiber generation; most of these biological processes involve cytokines, growth factors and extracellular matrix proteins (5). One explanation is that surgical trauma initiates a wound-healing response provoking lens cells to release numerous cytokines, which contribute to visual deprivation often seen in PCO patients. For example, transforming growth factor $\beta_{2}$ (TGF- $\left.\beta_{2}\right)$ has attracted much attention in this field (6). TGF- $\beta_{2}$ belongs to the TGF- $\beta$ growth factor family, which regulates many aspects of cellular functions, including cell growth, differentiation, inflammation, cell migration and wound healing $(1,7,8)$. There are three members of the TGF- $\beta$ family, termed TGF- $\beta_{1}$, TGF- $\beta_{2}$ and TGF- $\beta_{3}(9)$. Among these, TGF- $\beta_{2}$ is the major isoform present in human lens epithelial cells (HLECs). Recent studies have shown a close relationship between TGF- $\beta_{2}$ and PCO formation. It has been reported that TGF- $\beta_{2}$ may regulate HLEC trans-differentiation and matrix contraction $(5,6)$, promote HLEC adhesion and migration (10) and enhance matrix metalloproteinase (MMP) activities in vitro $(3,11)$, all of which may contribute to $\mathrm{PCO}$ formation.

In the present study, we showed that dexamethasone (DEX) inhibits TGF- $\beta_{2}$-induced HLE-B3 cell migration in vitro, possibly via the down-regulation of the expression of MMPs and the inhibition of mitogen-activated protein kinase (MAPK) pathway. We, therefore, propose that administration of DEX may be helpful to reduce the incidence of PCO.

\section{Materials and methods}

Reagents. TGF- $\beta_{2}$ was purchased from Sigma-Aldrich (St. Louis, MO, USA). DEX was obtained from the Affiliated Ophthalmic Hospital of Nanjing Medical University. Anti-phospho-ERK1/2 
$(1: 1,000)$ and anti-ERK $(1: 1,000)$ antibodies were purchased from Cell Signaling Technology (Beverly, MA, USA). GAPDH $(1: 10,000)$ antibody was purchased from Santa Cruz Biotechnology (Santa Cruz, CA, USA) and PD98059 was purchased from Calbiochem (Gibbstown, NJ, USA).

Cell culture. The HLE-B3 cell line was obtained from Dr Fu Shang at Tufts University. HLE-B3 cells were maintained in Dulbecco's modified Eagles's medium (DMEM; Gibco Life Technologies) supplemented with $10 \%$ FBS, penicillin/ streptomycin (1:100; Sigma), 4 mM L-glutamine and $0.19 \%$ HEPES. Cells were reseeded in 60-mm dishes (Falcon; Becton-Dickinson Labworks, Oxnard, CA, USA) at a density of $2 \times 10^{6}$ cells/dish with fresh complete culture medium. When almost confluent, the cells were starved in serum-free DMEM overnight prior to treatment.

Cell migration assay. To determine HLE-B3 cell migration, a Phagokinetic Track Motility Assay was performed, as previously described (12). Cultured HLE-B3 cells were deprived of serum and treated with TGF- $\beta_{2}(0.1 \mathrm{ng} / \mathrm{ml})$ or PD98059 $(10 \mu \mathrm{M})$, with or without DEX $(100 \mathrm{nM})$. When cells were $70-80 \%$ confluent, 12 -well plates were coated with fibronectin (20 $\mu \mathrm{g} / \mathrm{ml}$ in PBS; Sigma) and stored for at least $2 \mathrm{~h}$ at $37^{\circ} \mathrm{C}$. After removing the coating medium, the wells were washed with PBS $\left(4^{\circ} \mathrm{C}\right)$ one time. Microsphere suspension $(2.4 \mathrm{ml})$ (86 $\mu \mathrm{l}$ stock microbead solution in $30 \mathrm{ml}$ PBS) was added to each well. The plates were centrifuged at $1,200 \mathrm{rpm}$ at $4^{\circ} \mathrm{C}$ for $20 \mathrm{~min}$ immediately and carefully transferred to a $\mathrm{CO}_{2}$ incubator and incubated at $37^{\circ} \mathrm{C}$ for at least $1 \mathrm{~h}$. Coated plates should be used within $2 \mathrm{~h}$ after removal from the centrifuge. The supernatant $(1.8 \mathrm{ml})$ was removed from each well and finally 1,500 freshly trypsinized cells in $2 \mathrm{ml}$ assay-medium (DMEM with $0.05 \%$ FBS) were seeded per well. Cells with or without treatment were cultured for $24 \mathrm{~h}$ and photographed.

Gelatin zymography. MMP-2 and MMP-9 activities were determined by zymography, measuring gelatinolytic activity in culture media. Briefly, cells were incubated according to the desired time, the supernatant $(15 \mu \mathrm{l})$ was diluted with zymography sample buffer $(5 \mu \mathrm{l})$ and loaded onto $10 \%$ gelatin gel (Criterion; Bio-Rad, Hercules, CA, USA). Gels were run at $\sim 90 \mathrm{~V}$ at $4^{\circ} \mathrm{C}$. After electrophoresis, the gel was gently washed in washing buffer $(50 \mathrm{mM}$ Tris- $\mathrm{HCl}, \mathrm{pH} 7.4,5 \mathrm{mM}$ $\mathrm{CaCl}_{2}, 1 \mu \mathrm{M} \mathrm{ZnCl}_{2}$ and $2.5 \%$ Triton $\mathrm{X}-100$ ) for $2 \times 15 \mathrm{~min}$ at room temperature to remove SDS from the gel, and the gel was incubated in zymogram incubation buffer (1.0\% Triton X-100 in Tris Soln) for $24 \mathrm{~h}$ at $37^{\circ} \mathrm{C}$ with gentle agitation, stained with $0.1 \%$ Coomassie Brilliant Blue R-250 for 1-3 h, then destained. Clear bands against the blue background indicated the presence of gelatinolytic activity. Quantification of bands was performed by densitometry.

RT-PCR assay. Semi-quantitative (RT-PCR) was used to measure MMP-2 and MMP-9 mRNA levels, and $\beta$-actin mRNA levels were used as controls. Total RNA was isolated from cells with an RNA isolation kit (RNAzol, Tel-Test, Friends-wood, TX) and reverse-transcribed according to the manufacturer. PCR was performed with an initial denaturation for $30 \mathrm{sec}$ at $94^{\circ} \mathrm{C}$, annealing at $58^{\circ} \mathrm{C}$ for $30 \mathrm{sec}$ and extension at $72^{\circ} \mathrm{C}$ for $45 \mathrm{sec}$, for 29 cycles. Primer sequences used were as follows: $\beta$-actin forward CTACAATGAGCTGCGTGTGGC; $\beta$-actin reverse CAGGTCCAGACGCAGGATGGC; MMP-2 forward ACCTACACCAAGAACTTCCG; MMP-2 reverse TTGGTTCTCCAGCTTCAGGT; MMP-9 forward CCCATTTCGACGATCAC; MMP-9 reverse GGCACTGAC CAATGATCTAAGC. PCR products were separated by $2 \%$ agarose gel electrophoresis and visualized with ethidium bromide. The bands were quantified by densitometry and normalized with $\beta$-actin levels.

Western blot analysis. Cultured HLE-B3 cells were deprived of serum and treated with TGF- $\beta_{2}(0.1 \mathrm{ng} / \mathrm{ml})$ or PD98059 $(10 \mu \mathrm{M})$, with or without DEX $(100 \mathrm{nM})$. When cells were grown to $70-80 \%$ confluence, they were incubated at $37^{\circ} \mathrm{C}$ for $3 \mathrm{~h}$ before measurement. After that, HLE-B3 cells with and without treatment were washed with cold PBS, lysed and $20 \mu \mathrm{g}$ of cellular proteins were resolved on $10 \%$ SDS-PAGE gel, then transferred to polyvinylidene difluoride (PVDF) membranes (Millipore, Milford, MA, USA). The proteins were detected using the indicated antibodies.

Statistical analysis. Statistica 6.0 (Statsoft, Inc., Tulsa, OK, USA) was used to perform all statistical analyses, using one way ANOVA followed by a post-hoc Newman-Keuls comparison between the groups. $\mathrm{P}<0.05$ was considered to be statistically significant.

\section{Results}

DEX inhibits TGF- $\beta_{2}$-induced HLE-B3 cell migration. As we discussed earlier, TGF- $\beta_{2}$ is important for cell migration, and is a major contributor to PCO development. Inhibition of TGF- $\beta_{2}$-induced HLE cell migration may be beneficial for PCO prevention (10). We then tested the effects of DEX on HLE-B3 cell migration in response to TGF- $\beta_{2}$ treatment. As expected, we found that TGF- $\beta_{2}$ induced obvious HLE-B3 cell migration (Fig. 1B). Of note, this TGF- $\beta_{2}$-induced HLE-B3 cell migration was almost blocked by DEX treatment (Fig. 1C and D). Co-treatment of PD98059, a well-known ERK/MAPK signaling pharmacological inhibitor, also reversed TGF- $\beta_{2^{-}}$ induced cell migration (Fig. $1 \mathrm{E}$ and $\mathrm{F}$ ), which suggests that the ERK/MAPK pathway is involved in TGF- $\beta_{2}$-induced cell migration and the effect of DEX on cell migration may be due to the interference of this pathway.

DEX abolishes TGF- $\beta_{2}$-induced MMP-2 and MMP-9 mRNA up-regulation and MMP enzymatic activities. To further explore the possible mechanism of DEX's effect on TGF- $\beta_{2}-$ induced HLE-B3 cell migration, RT-PCR assay was used to measure the mRNA expression levels of MMP-2 and MMP-9. Similar to the findings of other laboratories $(3,11)$, we found that both MMP mRNA expression levels were increased after TGF- $\beta_{2}$ treatment for $24 \mathrm{~h}$. DEX almost blocked MMP mRNA up-regulation (Fig. 2). A gelatin zymography method was further used to measure the enzymatic activities of MMP-2 and MMP-9 in HLE-B3 cells. As shown in Fig. 3, TGF- $\beta_{2}$ increased the activities of MMP-2 and MMP-9 in the cell supernatant after $24 \mathrm{~h}$, and DEX treatment almost reversed this effect. 


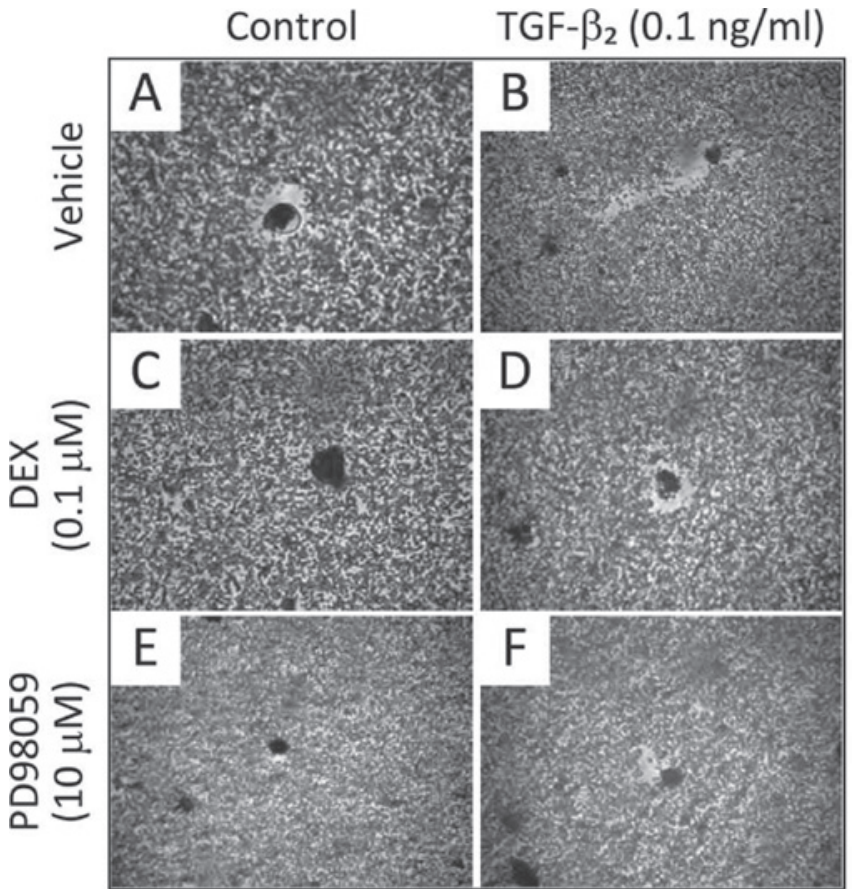

Figure 1. Migration of HLE-B3 cells induced by TGF- $\beta_{2}$ was inhibited by dexamethasone (DEX). Cells were treated with indicated treatments and the cell migration was measured by Phagokinetic Trackmotility Assay, as described in Materials and methods, and photographed after $24 \mathrm{~h}$. The images shown are representative from at least three independent experiments. (A) Vehicle control. (B) TGF- $\beta_{2}$-treated group. (C) DEX alone. (D) TGF- $\beta_{2}+$ DEX. (E) PD98059 alone. (F) TGF- $\beta_{2}+$ PD98059.

A

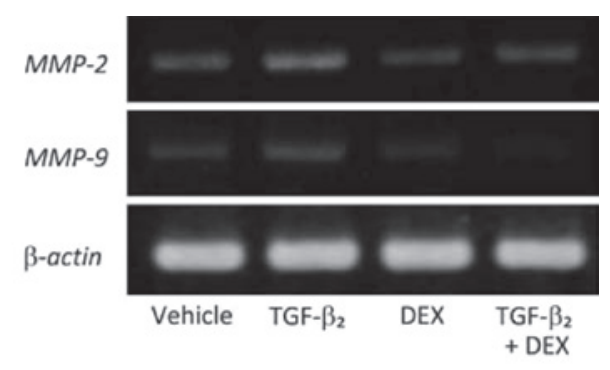

B

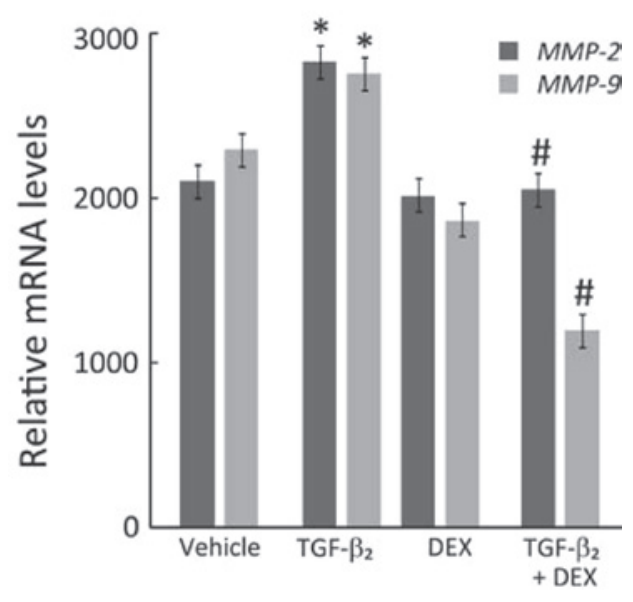

Figure 2. Dexamethasone (DEX) decreases TGF- $\beta_{2}$-induced MMP-2 and MMP-9 mRNA expression. (A) RT-PCR analysis of MMP-2, MMP-9 and $\beta$-actin mRNA expression. Cells were treated with TGF- $\beta_{2}(0.1 \mathrm{ng} / \mathrm{ml})$, or DEX $(100 \mathrm{nM})$, or both. The gel images shown are representative from at least three independent experiments. (B) Quantified data from gel images. The relative mRNA expression levels were normalized to loading controls ( $\beta$-actin). Data are expressed as the means \pm SEM. ${ }^{*} \mathrm{P}<0.05$; TGF- $\beta_{2}$ vs. control; ${ }^{\#} \mathrm{P}<0.05 ; \mathrm{TGF}-\beta_{2}+\mathrm{DEX}$ vs. TGF- $\beta_{2}$.
A

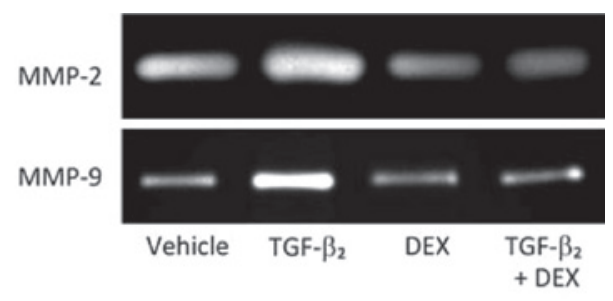

B

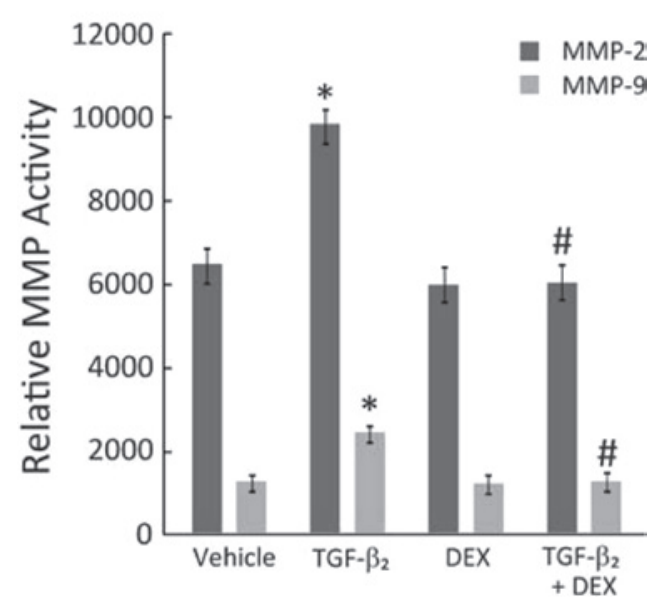

Figure 3. Dexamethasone (DEX) blocks TGF- $\beta_{2}$-induced MMP-2 and MMP-9 activities in HLE-B3 cells. (A) Cells were treated with vehicle, $0.1 \mathrm{ng} / \mathrm{ml}$ of TGF- $\beta_{2}, 100 \mathrm{nM}$ of DEX, or both, and were incubated in serumfree DMEM for $24 \mathrm{~h}$. After incubation, culture media were applied on a $10 \%$ SDS-polyacrylamide gel containing $1 \mu \mathrm{g} / \mathrm{ml}$ of gelatin. The clear zone on a blue background represented MMP activities. (B) The intensity of the bands was quantified by densitometry. Data is expressed as the means \pm SEM of at least six independent experiments with similar results. ${ }^{*} \mathrm{P}<0.05$; TGF- $\beta_{2}$ vs. control; ${ }^{\text {}} \mathrm{P}<0.05$; TGF- $\beta_{2}+$ DEX vs. TGF- $\beta_{2}$.

DEX inhibits TGF- $\beta_{2}$-induced activation of MAPK/ERK. Several reports have confirmed that TGF- $\beta_{2}$ leads to the activation of the MAPK/ERK pathway, which contributes to cell migration (12-14). Since our results demonstrated that DEX blocks TGF- $\beta_{2}$-induced HLC-B3 cell migration, it is possible that ERK/MAPK signaling may also be affected. To test this, the HLE-B3 cells were treated for $3 \mathrm{~h}$ with $0.1 \mathrm{ng} / \mathrm{ml}$ of TGF- $\beta_{2}$ in the presence or absence of $100 \mathrm{nM}$ of DEX. We found that TGF- $\beta_{2}$ treatment dramatically increased the phosphorylation of ERK1/2 (p-ERK1/2) levels determined by Western blot analysis (Fig. 4). This is consistent with the findings reported in the literature (12-14). DEX by itself did not affect or only slightly decreased the p-ERK1/2 levels. However, it appeared that DEX blocked the activation of the MAPK pathway by TGF- $\beta_{2}$, since in cells treated with both TGF- $\beta_{2}$ and DEX, the p-ERK1/2 levels were comparable to those of the control cells (Fig. 4). PD98059, the high selective inhibitor of MEK1/ERK activation, eliminated TGF- $\beta_{2}$-induced elevation of $\mathrm{p}$-ERK (Fig. 4). Treatment of HLE-B3 cells with TGF- $\beta_{2}$ or DEX did not alter the phosphorylation of JNK or p38 proteins in the MAPK family (data not shown). Taking into consideration our previous finding that inhibition of ERK1/2 activation by PD98059 blocked TGF- $\beta_{2}$-induced cell migration, these results support a model that TGF- $\beta_{2}$ induces HLE cell migration through activation of the MAPK pathway, which in turn increases MMP gene expression and hence MMP enzymatic activities. DEX inhibits TGF- $\beta_{2}$-induced HLE cell migration 
A
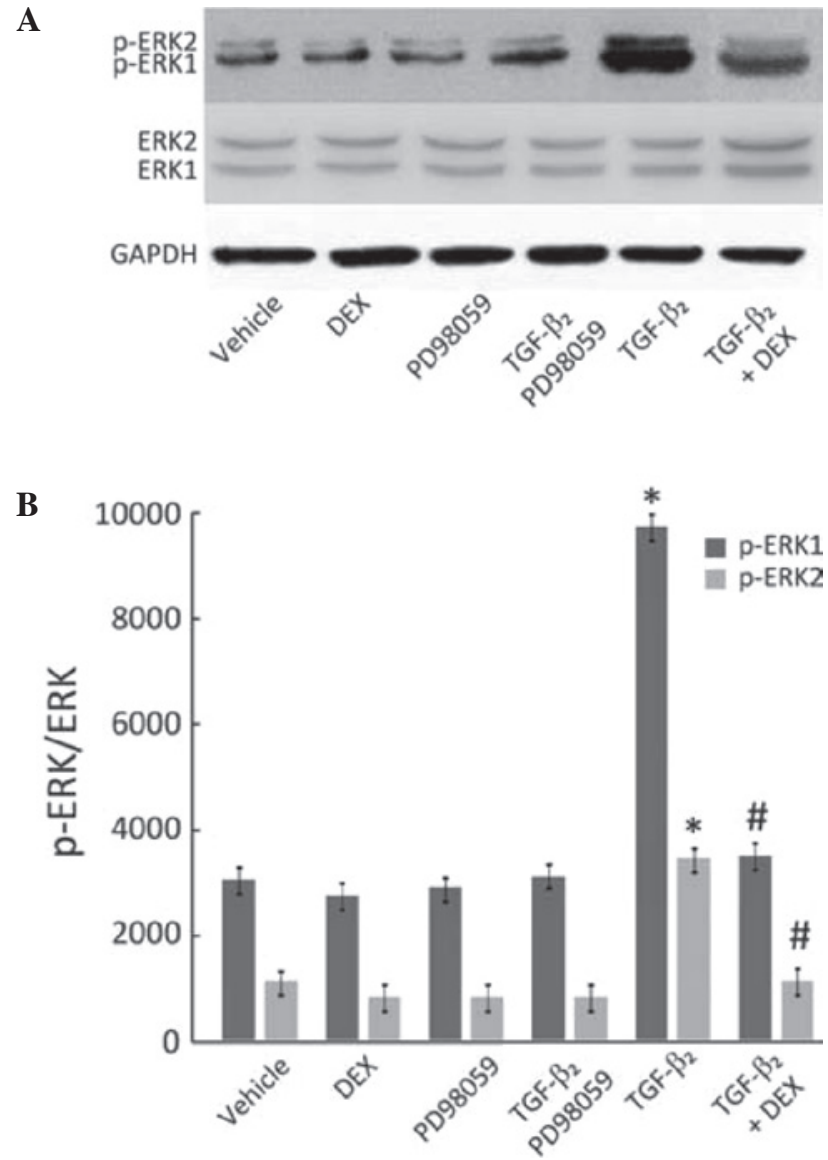

Figure 4. Effect of Dexamethasone (DEX) on TGF- $\beta_{2}$-induced phosphorylation of the MAPK/ERK signaling pathway. (A) Western blots of cell extracts of HLE-B3 treated with TGF- $\beta_{2}(0.1 \mathrm{ng} / \mathrm{ml})$, PD98059 $(10 \mu \mathrm{M})$, DEX $(100 \mathrm{nM})$ and indicated combinations. The phosphorylated and total protein levels of ERK1/2 were detected with specific antibodies. Images shown are representative from at least three independent experiments with similar results. (B) Densitometry analysis of Western blotting results. The results are the means \pm SEM. ${ }^{~} \mathrm{P}<0.05$; TGF $-\beta_{2}$ vs. control; ${ }^{*} \mathrm{P}<0.05 ;$ TGF- $\beta_{2}+$ DEX vs. TGF- $\beta_{2}$.

by blocking ERK/MAPK activation and subsequently MMP activities.

\section{Discussion}

To date, the only effective treatment for PCO is Nd:YAG laser capsulotomy. However, it carries other complications and risks (1), and is difficult to perform on children and infant patients. Therefore, pharmacological prevention of PCO is considered a valuable therapeutic strategy for patients undergoing cataract surgery.

Since the 1970's, many agents, including DEX, have been tested for this purpose, both in vitro and in vivo, but most trials were considered to be unsuccessful (15). Results from studies choosing DEX to evaluate PCO formation are controversial. In an in vitro study, DEX was shown to inhibit lens cell proliferation (16). However, an in vivo rat study found that DEX had only a minor effect in preventing PCO formation (17). One animal study using cultured rat lens explants found that DEX did influence lens cell behavior, helped transient formation of needle-like cells, cell coverage and retention of a monolayer of migratory cells surrounding PCO-like plaques, suggesting that
DEX may even act in favor of PCO formation (18). However, another clinical observation found that topical instillation of DEX did not influence the formation of PCO 2 years after cataract surgery (19).

TGF- $\beta_{2}$ has been widely recognized as one of the major factors contributing to the formation of PCO. As reported in the literature, TGF- $\beta_{2}$ appears to play several roles in HLEC behavior, such as the regulation of HLEC trans-differentiation and matrix contraction, the promotion of HLECs adhesion and migration and the enhancement of MMP-2 and MMP-9 activities. Most of these conclusions are drawn from in vitro studies, but it is also possible that the high concentration of TGF- $\beta_{2}$ in aqueous humor accompanying surgery may also play a key role in PCO formation, as our finding that TGF- $\beta_{2}$ is dramatically increased topically in patients shortly after cataract surgery.

Notably, we found that DEX counteracts TGF- $\beta_{2}$ action in vitro as well. For example, the present results showed that the capacity of HLE-B3 cell migration was enhanced by TGF- $\beta_{2}$, but was blocked by DEX (Fig. 1). Given the fact that cell migration of HLECs plays a key role in the remodeling of the lens capsule $(20,21)$ and is correlated with MMP activity within the lens (11), we also investigated the relationships among TGF- $\beta_{2}$, MMPs and DEX. Our data suggest that TGF- $\beta_{2}-$ induced up-regulation of MMP-2 and MMP-9 activities was reversed by DEX (Fig. 3). In fact, DEX inhibited not only the activation of MMP-2 and MMP-9, but also the synthesis of these enzymes at the mRNA levels (Fig. 2), suggesting that the effect of DEX on HLE cell migration is associated with the repression of MMP-2 and MMP-9 transcription. Furthermore, DEX inhibited the TGF- $\beta_{2}$-induced phosphorylation of ERK (Fig. 4), but not JNK and p38 in HLECs. It is worth to note that PD98059, a control agent used in this study, was also shown to inhibit TGF- $\beta_{2}$-induced HLE-B3 cell migration, while PD98059 itself did not alter the cell migration behavior and only slightly reduced the basal phosphorylation levels of ERK (Figs. 1 and 4). This warrants further testing on the effects of small-molecule MAPK inhibitors on PCO formation. Previously, we demonstrated that EGF induces MMP-2 expression and cell migration through ERK and PI3/AKT pathways in cultured HLEC and inhibition of EGFR, ERK and PI3 kinase reduces MMP-2 expression and cell migration (22). Taken together, the present data support a model where DEX blocks TGF- $\beta_{2}$-induced cell migration through inhibition of the ERK/MAPK signaling pathways, indicating that DEX may indeed be one of the appropriate options for PCO prevention and/or treatment.

\section{Acknowledgements}

This study was supported by a grant from the Natural Science Fund for Colleges and Universities in Jiangsu Province, China (08KJD310002, 07KJD320140), and a grant from the Nanjing Science and Technology Plan Projects (200801093).

\section{References}

1. Hellawell GO, Ho K, Halliwell M, et al: Long-term outcomes and morbidity after I125 brachytherapy for localised prostate cancer: an early UK series. Clin Oncol 17: 68-69, 2005. 
2. Awasthi N, Guo S and Wagner BJ: Posterior capsular opacification: a problem reduced but not yet eradicated. Arch Ophthalmol 127: 555-562, 2009.

3. Awasthi N, Wang-Su ST and Wagner BJ: Downregulation of MMP-2 and -9 by proteasome inhibition: a possible mechanism to decrease LEC migration and prevent posterior capsular opacification. Invest Ophthalmol Vis Sci 49: 1998-2003, 2008.

4. Awasthi $\mathrm{N}$ and Wagner BJ: Suppression of human lens epithelial cell proliferation by proteasome inhibition, a potential defense against posterior capsular opacification. Invest Ophthalmol Vis Sci 47: 4482-4489, 2006.

5. Wormstone IM, Anderson IK, Eldred JA, Dawes LJ and Duncan G: Short-term exposure to transforming growth factor beta induces long-term fibrotic responses. Exp Eye Res 83: 1238-1245, 2006.

6. Wormstone IM, Wang L and Liu CS: Posterior capsule opacification. Exp Eye Res 88: 257-269, 2009.

7. Hodge WG: Posterior capsule opacification after cataract surgery. Ophthalmology 105: 943-944, 1998.

8. Wormstone IM, Tamiya S, Anderson I and Duncan G: TGF-beta2-induced matrix modification and cell transdifferentiation in the human lens capsular bag. Invest Ophthalmol Vis Sci 43: 2301-2308, 2002.

9. Wormstone IM: Posterior capsule opacification: a cell biological perspective. Exp Eye Res 74: 337-347, 2002.

10. Yao K, Tan J, Ye P, et al: Integrin beta1-mediated signaling is involved in transforming growth factor-beta2-promoted migration in human lens epithelial cells. Mol Vis 13: 1769-1776, 2007.

11. Wong TT, Daniels JT, Crowston JG and Khaw PT: MMP inhibition prevents human lens epithelial cell migration and contraction of the lens capsule. Br J Ophthalmol 88: 868-872, 2004.

12. Kimoto K, Nakatsuka K, Matsuo N and Yoshioka H: p38 MAPK mediates the expression of type I collagen induced by TGF-beta 2 in human retinal pigment epithelial cells ARPE-19. Invest Ophthalmol Vis Sci 45: 2431-2437, 2004.
13. Kim D, Dan HC, Park S, et al: AKT/PKB signaling mechanisms in cancer and chemoresistance. Front Biosci 10: 975-987, 2005.

14. Saika S, Yamanaka O, Ikeda K, et al: Inhibition of p38MAP kinase suppresses fibrotic reaction of retinal pigment epithelial cells. Lab Invest 85: 838-850, 2005.

15. Walker TD: Pharmacological attempts to reduce posterior capsule opacification after cataract surgery - a review. Clin Exp Ophthalmol 36: 883-890, 2008

16. McDonnell PJ, Krause W and Glaser BM: In vitro inhibition of lens epithelial cell proliferation and migration. Ophthalmic Surg 19: 25-30, 1988.

17. Inan UU, Ozturk F, Kaynak S, et al: Prevention of posterior capsule opacification by intraoperative single-dose pharmacologic agents. J Cataract Refract Surg 27: 1079-1087, 2001.

18. Symonds JG, Lovicu FJ and Chamberlain CG: Differing effects of dexamethasone and diclofenac on posterior capsule opacification-like changes in a rat lens explant model. Exp Eye Res 83: 771-782, 2006.

19. Zaczek A, Laurell CG and Zetterstrom C: Posterior capsule opacification after phacoemulsification in patients with postoperative steroidal and nonsteroidal treatment. J Cataract Refract Surg 30: 316-320, 2004

20. Maziere C, Conte MA, Leborgne L, et al: UVA radiation stimulates ceramide production: relationship to oxidative stress and potential role in ERK, JNK, and p38 activation. Biochem Biophys Res Commun 281: 289-294, 2001.

21. Sugita M, Kato S, Sugita G and Oshika T: Migration of lens epithelial cells through haptic root of single-piece acrylicfoldable intraocular lens. Am J Ophthalmol 137: 377-379, 2004.

22. Jiang Q, Zhou C, Bi Z and Wan Y: EGF-induced cell migration is mediated by ERK and PI3K/AKT pathways in cultured human lens epithelial cells. J Ocul Pharmacol Ther 22: 93-102, 2006. 